\title{
Primary pulmonary synovial sarcoma presenting with a large lump mass in the left upper mediastinum: A case report
}

\author{
AI-GUI JIANG ${ }^{1}$, HONG YU ${ }^{2}$, XIAO-YAN GAO ${ }^{1}$ and HUI-YU LU ${ }^{1}$ \\ Departments of ${ }^{1}$ Respiratory Medicine and ${ }^{2}$ Pathology, Taizhou People's Hospital, Taizhou, Jiangsu 225300, P.R. China
}

Received January 25, 2015; Accepted February 25, 2016

DOI: $10.3892 /$ etm.2016.3237

\begin{abstract}
Primary pulmonary synovial sarcoma is a rare lesion that occurs in $0.5 \%$ cases of lung malignancies. Chest computed tomography (CT) reveals a heterogeneously enhancing mass in the lobe or hilum of the lungs, frequently calcified and with pleural invasion. Involvement of the mediastinum in the course of primary pulmonary synovial sarcoma, in particular detection of a large mass in the mediastinum as the sole initial imaging manifestation, is extremely rare, which may contribute to a delayed diagnosis or misdiagnosis. The present case report describes an extremely rare case of a patient with primary pulmonary synovial sarcoma presenting with a large mass in the left upper mediastinum. A 59-year-old patient was admitted to the Department of Respiratory Medicine of Taizhou People's Hospital in May 2014, complaining of a persistent cough and blood sputum for 2 weeks. Following admission, a chest CT showed a large mass in the left upper mediastinum. Thoracoscopy was performed and revealed that the left pulmonary artery was engulfed by the mass, and thus surgical resection of the tumor was abandoned. The patient was definitively diagnosed with primary pulmonary synovial sarcoma following the histopathological and immunohistochemical analysis of biopsy specimens obtained via thoracoscopy. Following the final diagnosis, the patient was transferred to the Department of Oncology for chemotherapy treatments with ifosfamide and doxorubicin. Unfortunately, no partial regression was achieved after two rounds of chemotherapy, and the patient was lost to follow-up 3 months after the diagnosis was confirmed. The present case may promote the consideration of primary pulmonary synovial sarcoma in the differential diagnosis of patients who present with a large mass in the mediastinum.
\end{abstract}

Correspondence to: Dr Ai-Gui Jiang, Department of Respiratory Medicine, Taizhou People's Hospital, 210 Yingchun Road, Taizhou, Jiangsu 225300, P.R. China

E-mail: jiangaigui@126.com

Key words: primary pulmonary synovial sarcoma

\section{Introduction}

Primary pulmonary synovial sarcoma is a rare lesion that occurs in $0.5 \%$ cases of lung malignancies (1). It is a highly aggressive malignant neoplasm that may arise from the lung parenchyma, bronchial tree or pulmonary arteries (1). It is more common in males and, unlike other malignancies, it has not been associated with cigarette smoking (1). The diagnosis of primary pulmonary synovial sarcoma requires clinical, radiological, pathological and immunohistochemical investigations to exclude alternative primary tumors and metastatic sarcoma (2). Immunohistochemistry and cytogenetic studies have reported an increasing incidence of primary synovial sarcomas among pulmonary synovial sarcomas (1-3).

Primary pulmonary synovial sarcoma has no diagnostic radiological features and the differential diagnosis of this tumor is very difficult. Chest computed tomography (CT) reveals a heterogeneously enhancing mass in the lobe or hilum of the lung, frequently calcified and with pleural invasion (4-6). However, involvement of the mediastinum, particularly presenting with a large lump mass in the mediastinum as the sole initial imaging manifestation, in the course of primary pulmonary synovial sarcoma is extremely rare, which may contribute to a delayed diagnosis or misdiagnosis. To the best of our knowledge, there are no prior reports describing a primary pulmonary synovial sarcoma presenting with a large lump mass in the mediastinum as the sole initial imaging manifestation in the English-language literature. The present study describes a case finally diagnosed as primary pulmonary synovial sarcoma, which initially manifested as a large lump mass in the mediastinum.

\section{Case report}

The present study was conducted in accordance with the Declaration of Helsinki and approved by the Ethics Committee of Taizhou People's Hospital (Jiangsu, China). Written informed consent was obtained from the patient. A 59-year-old patient was admitted to the Department of Respiratory Medicine of Taizhou People's Hospital in March 2014 complaining of a persistent cough and blood sputum for 2 weeks. The patient had no prior history of lung disease, but had a 30-year history of tobacco use, smoking one pack of cigarettes per day for 25 years. Following admission, physical examinations revealed a body weight of $65 \mathrm{~kg}$, body height of $173 \mathrm{~cm}$, body 

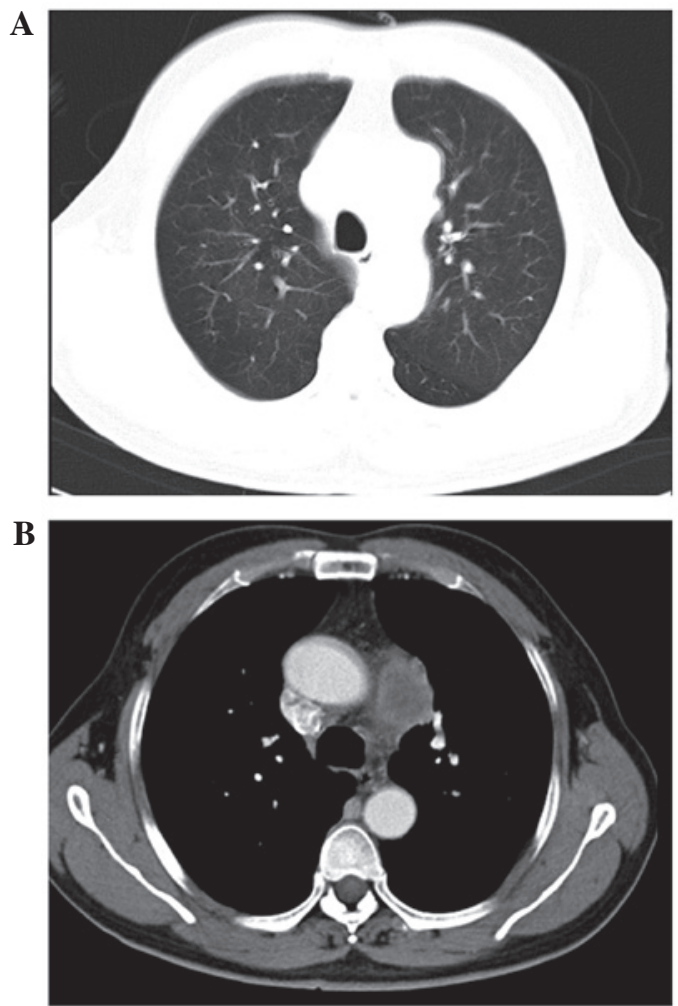

Figure 1. Computed tomography scan showed a large lump mass in left upper mediastinum, but no significant lesion in the left lung. (A) Lung window and (B) mediastinal window.

temperature of $37^{\circ} \mathrm{C}$, pulse of $86 \mathrm{bpm}$, respiratory rate of $18 \mathrm{bpm}$ and blood pressure of 110/72 $\mathrm{mmHg}$. The patient had yellow skin and bloodshot eyes, but no cyanosis of the lips. No enlargement of superficial lymph nodes of the neck and no abnormality was detected in the cardiopulmonary physical examination.

At the initial examination, laboratory results were as follows: Red blood cells, $3.98 \times 10^{12} / 1\left(4-5.5 \times 10^{12} / 1\right)$; hemoglobin, $118 \mathrm{~g} / 1$ (120-160 g/l); white blood cells, 4.57x10 $/ 1$ (4-10x $\left.10^{9} / 1\right)$; platelets, $121 \times 10^{9} / 1\left(100-300 \times 10^{9} / 1\right)$; and erythrocyte sedimentation rate, $23 \mathrm{~mm} / \mathrm{h}(0-15 \mathrm{~mm} / \mathrm{h})$. Biochemical examination revealed the following results: Total serum protein, $61.6 \mathrm{~g} / 1$ (66-87 g/l); albumin, $29.6 \mathrm{~g} / \mathrm{l}$ (35-54 g/l); globulin, $32 \mathrm{~g} / 1$ (20-40 g/l); C-reactive protein, $17 \mathrm{mg} / \mathrm{l}(0-5.0 \mathrm{mg} / \mathrm{l})$; serums carcinoembryonic antigen, $5.12 \mathrm{ng} / \mathrm{ml}(0-6.5 \mathrm{ng} / \mathrm{ml})$; neuron-specific enolase, $9.45 \mathrm{ng} / \mathrm{ml}$ $(0-20.0 \mathrm{ng} / \mathrm{ml})$; and CYFRA $21-1,1.21 \mathrm{ng} / \mathrm{ml}(0.1-3.3 \mathrm{ng} / \mathrm{ml})$. Chest CT revealed a large lump mass in left upper mediastinum (Fig. 1A and B). Thoracoscopy was performed and revealed that the left pulmonary artery was engulfed by the lump mass. As a result, the surgical resection of the tumor was abandoned. The patient was confirmed with a diagnosis of primary pulmonary synovial sarcoma following the histopathological and immunohistochemical analysis of biopsy specimens via thoracoscopy. Histologically, the lesion was composed of bundles of spindle-shaped cells, with areas of necrosis, sclerosis and hyalinosis (Fig. 2). Immunohistochemically, the tumor cells were positive for epithelial membrane antigen (EMA), CD99, B-cell lymphoma 2 (bcl-2) and vimentin (Figs. 3 and 4), but negative for S-100, SyN, Myo-D1 and CD20. Based on all

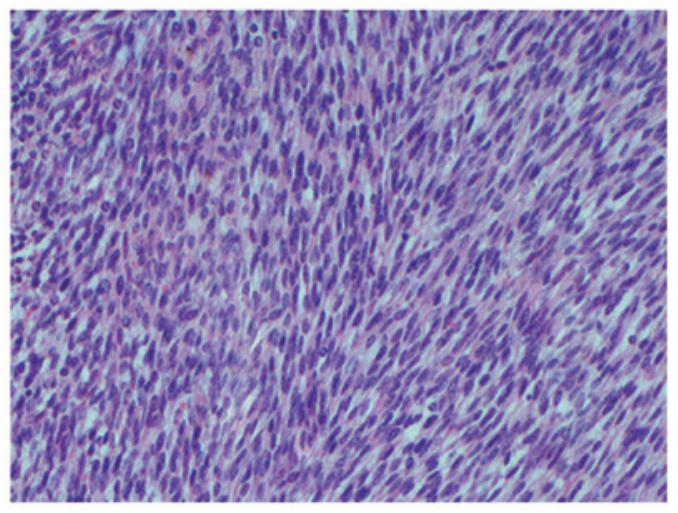

Figure 2. Histopathological analysis revealed the lesion was composed of bundles of spindle-shaped cells, with areas of necrosis, sclerosis and hyalinosis (stain, hematoxylin and eosin; magnification, $\mathrm{x} 100$ ).

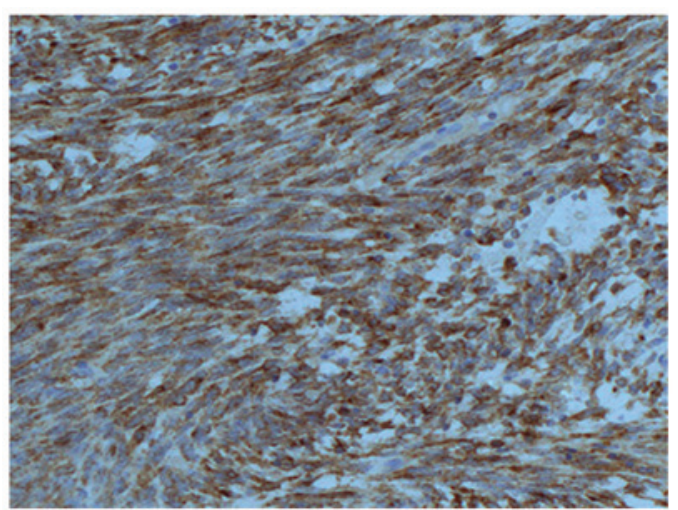

Figure 3. Immunohistochemical staining revealed the tumour cells were positive for B-cell lymphoma 2 (stain, hematoxylin and eosin; magnification, x200).

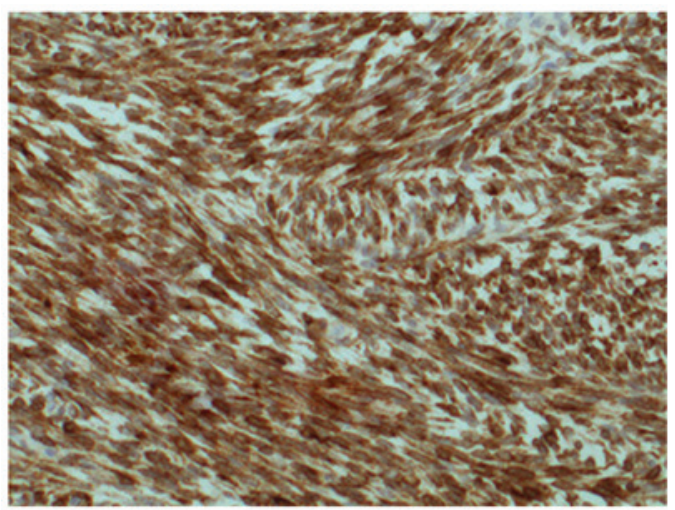

Figure 4. Immunohistochemistry staining revealed the tumour cells were positive for vimentin (stain, hematoxylin and eosin; magnification, x200).

of these findings, primary pulmonary synovial sarcoma was definitely diagnosed.

Following confirmation, the patient was transferred to the Department of Oncology for chemotherapy treatments with ifosfamide (2.5 g/ $/ \mathrm{m}^{2}$ i.v., day $\left.1-3\right)$ and doxorubicin $\left(25 \mathrm{mg} / \mathrm{m}^{2}\right.$ i.v., day 1-3), which were planned to be repeated every 21 days. Unfortunately, no partial regression was achieved after two rounds of chemotherapy, and the patient was lost to follow-up 3 months after diagnosis. 


\section{Discussion}

Primary pulmonary synovial sarcoma is rare, constituting $<0.5 \%$ of all pulmonary malignancies (7) and $\sim 10 \%$ of all primary pulmonary sarcomas (8). Primary pulmonary synovial sarcomas may arise from the parenchyma, tracheobronchial tree or pulmonary artery, and are designated as mesenchymal tumors in the World Health Organization classification (9).

Clinical symptoms of primary pulmonary synovial sarcoma may be associated with the histological type, region, size and degree of differentiation of the tumor (10). Patients suffering from primary pulmonary synovial sarcomas may have no overt symptoms during the initial stages; however, as the disease progresses, they are likely to present with a cough, chest pain caused by the tumor, hemoptysis from erosion of the airways and dyspnea caused by obstructive pneumonia (4).

Radiographic and subsequent CT imaging of the chest are typically conducted as primary investigative measures in the diagnosis of primary pulmonary synovial sarcoma. A chest CT scan showed that the majority of the masses were well-defined and measured $>5 \mathrm{~cm}$, displaying heterogeneous enhancement using intravenous contrast materials. Tumors of this type are often calcified and exhibit invasion of the pleura, resulting in pleural effusion $(4,11)$. To the best of our knowledge, involvement of the mediastinum, particularly presenting with a large lump mass in the mediastinum as the sole initial imaging manifestation, in the course of primary pulmonary synovial sarcoma is extremely rare, which may have been a factor in the delayed diagnosis or misdiagnosis. We speculate a number of possible causes: i) The tumor in the present case may have originated in the left pulmonary artery and grew to the left upper mediastinum; or ii) the characteristics of expansive growth, well-defined with coated or fake capsule formation of the tumor resulted in clear delineation between the tumor and the lung.

Diagnosis of primary pulmonary synovial sarcoma was based on pathological and immunohistochemical analyses, as well as physical and radiological examinations to exclude alternative primary tumors and metastatic sarcoma. Primary pulmonary synovial sarcomas are of four subtypes: Monophasic fibrous (spindle), monophasic epithelial, biphasic and poorly differentiated, among which the former two are most common (12). Immunohistochemical examination may be useful in differentiating synovial cell sarcomas from other sarcomas. In recent studies, synovial cell sarcomas were shown to be almost uniformly positive for vimentin and bcl-2, as well as positive for EMA in 55-91\% of cases, cytokeratin in $70 \%$, and CD99 in $90 \%(13,14)$. In the present case study, histological results revealed that the neoplastic cells were of moderate size with obvious nucleoli and thick cell membranes, as well as with varying arrangements of epithelial cells and spindle cells. The following immunohistochemical analysis revealed that the tumor cells were positive for EMA, bcl-2, CD99 and vimentin, but negative for S-100, SyN, Myo-D1 and CD20. On the basis of these results, primary pulmonary synovial sarcoma was diagnosed. Cytogenetic testing may be performed when diagnosis is unclear, which is a new diagnostic method for synovial sarcoma (15). The $\mathrm{t}(\mathrm{X} ; 18)(\mathrm{p} 11.2 ; \mathrm{q} 11.2)$ translocation, commonly identified in synovial sarcoma, results from the fusion of the SYT gene on chromosome 18 to either of two closely related genes, $S S X 1$ and SSX2, on chromosome X.

To the best of our knowledge, complete surgical resection is preferred therapy for patients with primary pulmonary synovial sarcoma. Recent studies reveal that patients able to undergo complete surgical resection have significantly improved survival compared with patients with positive surgical margins or unresectable tumors (16-18). Radiotherapy has no apparent effect on the control of local disease or overall survival. Chemotherapy reported in unresectable primary pulmonary synovial cell sarcoma is very rare and often administered in palliative cases where surgical resection is not possible (6). Spillane et al (19) reported that synovial sarcoma is chemosensitive to ifosfamide and doxorubicin, with an overall response rate of $\sim 24 \%$. The study formed the rationale for offering chemotherapy to patients with pulmonary synovial sarcomas. In response to the left pulmonary artery was wrapped by the tumor, the patient in the present case study was referred for palliative chemotherapy using ifosfamide and doxorubicin. Unfortunately, no partial regression was achieved after two rounds of chemotherapy and the patient was lost to follow-up 3 months after diagnosis.

In conclusion, primary pulmonary synovial sarcoma presenting with a large lump mass in the mediastinum as the sole initial imaging manifestation is extremely rare, which may have been a factor in the delayed diagnosis or misdiagnosis. In this situation, the raised awareness of diagnosis and knowledge concerning the clinical presentation of primary pulmonary synovial sarcoma are key factors in ensuring an immediate diagnosis and adequate intervention.

\section{References}

1. Devleena, Bansal V, Chaudhuri T and Roy S: Primary synovial sarcoma of lung. Lung India 31: 277-279, 2014.

2. Kim GH, Kim MY, Koo HJ, Song JS and Choi CM: Primary Pulmonary Synovial Sarcoma in a Tertiary Referral Center: Clinical Characteristics, CT, and 18F-FDG PET Findings, With Pathologic Correlations. Medicine (Baltimore) 94: e1392, 2015.

3. Teng XD and Kong M: Primary pulmonary soft tissue sarcoma. Zhonghua Bing Li Xue Za Zhi 41: 204-208, 2012 (In Chinese).

4. Jiang J, Zhou J and Ding W: Primary pulmonary synovial sarcoma, a rare primary lung neoplasm: Two case reports and review of the current literature. Respirology 13: 748-750, 2008.

5. Cabuk D, Ustuner B, Akgul AG, Acikgoz O, Yaprak B, Uygun B Topcu S and Muezzinoglu B: Primary synovial sarcoma of lung. Korean J Thorac Cardiovasc Surg 47: 306-309, 2014.

6. Falkenstern-Ge RF, Kimmich M, Grabner A, Horn H, Friedel G, Ott $\mathrm{G}$ and Kohlhäufl M: Primary pulmonary synovial sarcoma: A rare primary pulmonary tumor. Lung 192: 211-214, 2014.

7. Dennison S, Weppler E and Giacoppe G: Primary pulmonary synovial sarcoma: A case report and review of current diagnostic and therapeutic standards. Oncologist 9: 339-342, 2004.

8. Spraker MB, Bair E, Bair R, Connell PP, Mahmood U and Koshy M: An analysis of patient characteristics and clinical outcomes in primary pulmonary sarcoma. J Thorac Oncol 8: 147-151, 2013.

9. Weiss SW: Histological Typing of Soft Tissue Tumors. Sobin LH (ed). 2nd edition. Springer-Verlag, Berlin, pp7-14, 1994.

10. Liu K and Li W: Analysis of 19 cases of primary pulmonary sarcoma. Zhongguo Fei Ai Za Zhi 15: 375-380, 2012 (In Chinese).

11. Cai AQ, Chen JW, Zhou XG and Lin JB: CT diagnosis of primary sarcoma of lung. Han Shao Ji Bing Za Zhi 11: 10-12, 2004 (In Chinese).

12. Okamoto S, Hisaoka M, Daa T, Hatakeyama K, Iwamasa T and Hashimoto H: Primary pulmonary synovial sarcoma: A clinicopathologic, immunohistochemical and molecular study of 11 cases. Hum Pathol 35: 850-856, 2004. 
13. Hartel PH, Fanburg-Smith JC, Frazier AA, Galvin JR, Lichy JH, Shilo K and Franks TJ: Primary pulmonary and mediastinal synovial sarcoma: A clinicopathologic study of 60 cases and comparison with five prior series. Mod Pathol 20: 760-769, 2007.

14. Olsen SH, Thomas DG and Lucas DR: Cluster analysis of immunohistochemical profiles in synovial sarcoma, malignant peripheral nerve sheath tumor and Ewing sarcoma. Mod Pathol 19: 659-668, 2006

15. van de Rijn M, Barr FG, Collins MH, Xiong QB and Fisher C: Absence of SYT-SSX fusion products in soft tissue tumors other than synovial sarcoma. Am J Clin Pathol 112: 43-49, 1999.

16. Magné N, Porsin B, Pivot X, Tchiknavorian X, Marcy PY, Foa C, Otto J, Schneider M and Thyss A: Primary lung sarcomas: Long survivors obtained with iterative complete surgery. Lung Cancer 31: 241-245, 2001
17. Régnard JF, Icard P, Guibert L, de Montpreville VT, Magdeleinat P and Levasseur P: Prognostic factors and results after surgical treatment of primary sarcomas of the lung. Ann Thorac Surg 68: 227-231, 1999.

18. Trassard M, Le Doussal V, Hacène K, Terrier P, Ranchère D, Guillou L, Fiche M, Collin F, Vilain MO, Bertrand G, et al: Prognostic factors in localized primary synovial sarcoma: A multicenter study of 128 adult patients. J Clin Oncol 19: 525-534, 2001.

19. Spillane AJ, A'Hern R, Judson IR, Fisher C and Thomas JM: Synovial sarcoma: A clinicopathologic, staging and prognostic assessment. J Clin Oncol 18: 3794-3803, 2000. 